\title{
I DON'T NEED PEER-SUPPORT: EFFECTIVE TUTORING IN BLENDED LEARNING ENVIRONMENTS FOR LEARNERS STUDYING VOCATIONALLY ORIENTATED DEGREES
}

\author{
Andrew Youde \\ The University of Huddersfield (UNITED KINGDOM)
}

\begin{abstract}
This paper proposes a module approach to teaching, learning, assessment and support for learners undertaking part-time, vocational degrees. Constructivist models of e-learning predominantly promote opportunities for peer interaction within formal, online university learning environments. Given the rise of social media engagement within society, there are challenges for tutors in blended and online contexts to provide opportunities for social constructivist learning experiences. This research proposes an alternative approach for a social media rich external environment. A mixed methods approach was adopted to conduct a detailed exploration of eight tutors' practice with data gathered from three principal sources. Interviews with tutors explored their approaches to delivery and considered factors that impacted on quality; students' perceptions of their learning experiences were assessed using an attitude survey; an analysis of the content and communications in the virtual learning environment provided insight into tutors' online practice. The research is based at a 'post 1992' university in the north of England with the School of Education. Analysis of tutors' modules suggested limited online peer-to-peer interaction with them noting the difficulties promoting engagement. The paper argues that 'Individual Constructivist Approaches' were favoured by learners within the formal course confines, with a need for tutors to promote a simple module structure focused around assessment that creates 'space' for learning. In today's social media rich society these findings could aid course design for similar contexts and learners. Further, it could support tutors in online and blended environments to design and deliver modules.
\end{abstract}

Keywords: Blended Learning, Constructivism.

\section{INTRODUCTION}

This paper reports an interesting outcome of a piece of research into effective tutors and tutoring within blended learning contexts. Blended learning typically involves significant online teaching, learning and support but includes some face-to-face contact [1]. The research conducted a detailed exploration of eight tutors' teaching, learning, assessment and learner support on one of their modules, which formed approximately $6 \%$ of a learner's degree. The research focused on part-time (PT) learners, undertaking vocationally relevant degrees whilst, usually, in full-time (FT) employment. Literatures note the difficulties when tutoring these learners, particularly regarding the influence of daily events within their lives, together with the pressures and time constraints of work [2]. However, adult learners tend to understand what they want to achieve from education and have clearer goals in mind [3]. Social Constructivist models of e-learning commonly promote opportunities for peer interaction within online, formal university learning environments [4;5]. The research noted difficulties for tutors in engaging learners in peer interaction and collaboration in online learning environments on their modules - within the Virtual Learning Environment (VLE), for example. As a result, this paper proposes a module approach to teaching, learning, assessment and support for these particular learners.

The research underpinning this paper found that learners valued teaching, learning and assessment that was generally aligned with the Individual Constructivist Perspective [6], with a facilitative teaching style adopted as an overall approach to module delivery. To complement this style, learning outside face-to-face sessions was focused on module assessment tasks with these linked to learners' work practice and were either case method or problem-based. The research found that effective tutors, as judged by their learners, were proactive in providing learner support, which opened opportunities for dialogue. This paper firstly notes the research context before a brief overview of the development and justification of the adopted research methods. The conceptual framework that underpinned the analysis of the tutors' modules is justified with the findings then presented. The conclusions suggest an approach to delivering modules appropriate for these particular learners who are likely to be 
managing the competing pressures of work and family life. Finally, a key area of further research is proposed.

\section{RESEARCH CONTEXT}

The research is based at a 'post 1992' university in the north of England which has approximately 520 full-time academic staff and 20,000 students. Blended learning delivery models were used on each course investigated and all were located in the School of Education, therefore, focused on this particular subject area. The courses adopted a day school model of delivery where learners typically attend classes one day per month with the remaining time spent studying independently, utilising resources held on the VLE. As stated above, the research conducted a detailed exploration of eight tutors' practice on one of their modules, which are usually a term in length (approximately three to four months) from the first day school until learners submit summative assessments. Tutors then have three weeks in which to mark their assignments and feedback. Each module, therefore, has two or three day schools with the overall course structure and delivery models developed by tutors and course leaders in conjunction with course approval committees. During a module, tutors have responsibility for teaching, assessment and monitoring learner progress. They are required to prepare suitable learning materials for both online contexts and day schools. Module syllabi and assessments, again, are developed by tutors and course leaders in conjunction with course approval committees. This includes both summative assessments and one opportunity for learners to receive feedback on a piece of formative assessment per module. Beyond this, tutors have autonomy in a number of aspects of teaching and learning. Day school content and teaching methods are solely within the control of the tutor who can structure delivery as they choose. Any further learning activities within a module, including online learning, are designed by module tutors and used at their discretion.

\section{DEVELOPMENT AND JUSTIFICATION OF THE ADOPTED RESEARCH METHODS}

A mixed methods approach [7] was adopted to conduct a detailed exploration of eight tutors' practice with data gathered from three principal sources. Interviews with tutors explored their approaches to delivery and considered factors that impacted on quality; students' perceptions of their learning experiences were assessed using an attitude survey; and, an analysis of the content and communications in the virtual learning environment provided insight into online practice.

The tutors' interviews explored their approaches to teaching and assessment whilst considering factors that influenced the success of the modules. To complement the interviews, a random selection of their students ( $n=72$ covering the eight modules investigated) completed a questionnaire which explored perceptions of their tutor. The questionnaire was designed to elicit general opinion about the quality of tutoring and to obtain this, a modified version of the Course Experience Questionnaire (CEQ) was used [8]. The scale items adopted were good teaching communication; good teaching feedback on, and concern for, student learning; clear goals and standards; and appropriate workload, with additional scales for the online elements of modules.

\section{CONCEPTUAL FRAMEWORK TO EXPLORE EFFECTIVE TEACHING IN BLENDED LEARNING CONTEXTS}

In order to evaluate effective practice reference is made to Biggs' Constructive Alignment Model [9] in which all components of teaching and learning are congruent or aligned. Mayes and de Freitas [6] draw on Biggs' Model [9] when they present three broad theoretical perspectives to inform online and blended learning design. The perspectives have their origin in established education theory traditions $[6$, p. 7], which further strengthen their value in evaluating blended learning contexts. The HE student learning context involves networks of users sharing content and tools [10], and Web 2.0 technologies afford greater collaboration [11, p. 157] in both formal and informal computer mediated communications (CMCs). Effective teaching within HE has been broadly understood as focused on students and their learning [12, p. 112] and both Biggs' and Mayes and de Freitas' recommendations are consistent with this view and relevant for the student context.

Constructivist learning theory underpins Biggs' Model to indicate the level of understanding that is anticipated from the teaching experience. For example, is the aim for memorisation or analysis of a particular issue? Whatever the aim, it is important that learners construct their own understanding, 
and in their own way, for a teaching experience to be considered effective [9, p. 27]. Biggs [9, p. 26] argues that when the following components are aligned, teaching is likely to be more effective:

- curriculum;

- teaching methods;

- assessment;

- climate teachers create with their interactions with students;

- institutional climate.

An imbalance between these components can lead to poor teaching and Surface approaches to study, where learners complete only the required activities in order to achieve desired outcomes [13, p. 138]. When all components are working towards a common goal, it is more likely that Deep approaches are adopted where learners use the highest level of learning activities [13, p. 138]. For example, lectures may not be the most appropriate way to encourage trainee teachers to see the value of small group work. A more suitable approach to achieve the session's aims and encourage deeper approaches to study may be participation in group work activities with reflection on the experience afterwards $[9, \mathrm{p}$. 27].

Effective teaching must continue to evolve so it reflects and responds to the context in which the teaching and learning is occurring [12, p. 111). When aligned, teaching is likely to be more effective $[9$, p. 26] and Mayes and de Freitas' [6, p. 7] perspectives suggest suitable approaches to online and blended learning contexts. Their three broad theoretical perspectives on learning are:

- The associationist/empiricist perspective (learning as activity);

- The constructivist perspective ${ }^{1}$ (learning as achieving understanding through individual or social approaches);

- The situative perspective (learning as social practice).

Mayes and de Freitas [6, p. 20] state, "most implementations of e-learning will include blended elements that emphasise all three levels: learning as behaviour, learning as the construction of knowledge and meaning, and learning as social practice", and this was found in the modules investigated as part of the research. The Constructivist perspective is now outlined with discussion of its alignment, particularly with regard to teaching, learning and assessment in blended and online contexts. This perspective showed most congruence with the teaching, learning and assessment found on the eight modules investigated.

The Constructivist Perspective has both an individual and social focus to allow learning as achieving understanding in individual and collaborative contexts [6, p. 220]. Fox [15, p. 31] argues that it is important for tutors to realise students are always trying to make sense of their study in terms of what they already know. This was relevant for the learners in the research study who were trying to apply their learning to work practices, organisational issues and a turbulent external environment $[16, p .8]$. The learners were professionals and brought a breadth of existing knowledge, understanding and experiences to the classroom [15, p. 29], and this highlights the relevance of exploring constructivist learning theory for the research.

The Individual Constructivist Perspective highlights the achievement of understanding through active discovery where learners construct new ideas by hypothesis testing. The pedagogy aligning with this perspective includes interactive environments for knowledge expansion, cognitive scaffolding, experimentation with the discovery of principles, adaptation of teaching to existing student understanding, and support for reflection, analysis and evaluation. Assessment strategies aligning with this perspective encourage experiential learning, experimental learning, problem-based learning, case-based learning and self-evaluation, and autonomy in learning. When evaluating tutor practices as part of the research I considered this perspective primarily focused on students generally learning independently from tutors and peers throughout modules. However, tutors provided support to

\footnotetext{
${ }^{1}$ Mayes and de Freitas [17] originally termed this the cognitive perspective but this has since been developed in the course of work in e-learning and pedagogy funded by Jisc.
} 
learners, engaged in dialogue regarding learning and assessment, but with limited peer interaction and collaboration occurring outside face-to-face contexts.

The Social Constructivist Perspective highlights the achievement of understanding through collaboration and dialogue. The pedagogy aligning with this perspective includes interactive and collaborative environments leading to conceptual development; support for reflection, peer review and evaluation; and experimentation with shared discovery. Assessments aligning with this perspective are common to the Individual Constructivist Perspective, however, include consideration of collaborative activities, participation, peer review and shared responsibility. When evaluating tutor practices as part of the research I considered that this perspective included a far greater focus on peer collaboration throughout teaching, learning and assessment, particularly outside face-to-face contexts and within online learning environments, such as the VLE.

Fox [15, p. 25] warns against adopting extreme statements about learning such as "all knowledge is socially constructed" and reminds us that individual and social approaches co-exist. During the analysis of tutor practices, I was mindful of this and used these categories as broad indicators of the overall approaches being adopted in relation to learner perceptions of their experience.

\section{FINDINGS}

\subsection{Introduction}

A significant theme that developed throughout the analysis was that higher CEQ scores were noticed where tutors' module approach aligned with the Individual Constructivist Perspective. Whereas, tutors exhibiting a greater number of practices aligning with the Social Constructivist Perspective, received mixed CEQ scores. This research further discerned that on all modules, teaching, learning and assessment were congruent [9], student-centred pedagogy being aligned with problem-based assessments.

This section begins with an overview of tutor CEQ scores, which provided insight into learner perceptions of the module. The section then provides evidence and discussion to support the key finding that effective tutor's approaches (as indicated by CEQ scores) align with the Individual Constructivist Perspective.

\subsection{Tutor CEQ Scores}

The CEQ provided feedback on tutor effectiveness on the modules and measured learner perceptions of teaching and assessment. Learners gave answers to five-point Likert scale questions with the results detailed in Table 1.

Table 1 - Tutor's Course Experience Questionnaire Results - Mean and (Standard Deviation).

\begin{tabular}{|l|c|c|c|c|l|l|}
\hline $\begin{array}{l}\text { Tutor } \\
\text { (Pseudonym) }\end{array}$ & N & CEQ Total & $\begin{array}{l}\text { Clear Goals } \\
\text { and } \\
\text { Standards }\end{array}$ & $\begin{array}{l}\text { Good Teaching } \\
\text { Communication }\end{array}$ & $\begin{array}{l}\text { Good } \\
\text { Teaching } \\
\text { Feedback }\end{array}$ & $\begin{array}{l}\text { Appropriate } \\
\text { Workload }\end{array}$ \\
\hline Ann & 6 & $4.06(0.36)$ & $4.29(0.40)$ & $4.50(0.35)$ & $4.25(0.45)$ & $3.71(0.68)$ \\
Bill & 7 & $3.86(0.64)$ & $3.96(1.09)$ & $4.33(0.69)$ & $3.93(0.72)$ & $3.89(0.66)$ \\
Claire & 7 & $4.10(0.35)$ & $4.29(0.57)$ & $4.62(0.36)$ & $3.64(0.35)$ & $4.25(0.64)$ \\
Daisy & 4 & $3.23(0.45)$ & $3.69(0.24)$ & $3.58(0.74)$ & $2.87(1.18)$ & $2.94(0.31)$ \\
Emily & 15 & $3.99(0.26)$ & $4.42(0.28)$ & $4.15(0.44)$ & $4.12(0.44)$ & $3.48(0.47)$ \\
Frank & 5 & $3.43(0.37)$ & $3.45(0.62)$ & $4.00(0.97)$ & $3.30(0.67)$ & $2.90(0.88)$ \\
George & 14 & $3.55(0.40)$ & $3.59(0.74)$ & $4.31(0.53)$ & $3.68(0.56)$ & $2.99(0.55)$ \\
Harry & 14 & $3.42(0.67)$ & $3.42(1.15)$ & $3.55(1.06)$ & $3.13(0.80)$ & $3.46(0.47)$ \\
\hline Mean & & $3.72(0.53)$ & $3.89(0.83)$ & $4.12(0.79)$ & $3.73(0.77)$ & $3.38(0.63)$ \\
\hline
\end{tabular}


Preliminary analysis revealed generally high scores across scales indicating learners feel their tutors are effective. The CEQ total scores are high with relatively small standard deviations for a five point scale, which suggested a common perception from the groups of learners. Tutor interview data also suggested learners were achieving on modules, and this corresponded with the generally high satisfaction outlined in the CEQ. Tutors Ann, Bill, Claire and Emily received the higher CEQ scores, with their approaches involving limited peer interactions, whereas Daisy, Frank, George and Harry receiving lower scores, who tried to adopt greater social constructivist approaches. The following section unpacks this key finding.

Overall pass rates, whilst a crude measure of educational success, were found to be greater than $95 \%$ with some of the remaining $5 \%$ expected to complete in the near future. Learners were asked to rate their module achievement on a five-point scale (very disappointed to very good) and the resultant mean score was 3.83 indicating broad satisfaction with their results and academic development. During the interviews, when tutors were asked to provide an overall impression of their groups, and there was a consensus around motivated learners, engaged in their study, and producing good quality work. These indicators, together with the generally high CEQ scores received, suggest successful modules with students learning, engaging and achieving.

\subsection{Tutors' Approaches to Teaching, Learning, Assessment and Learner Support}

\subsubsection{Teaching}

Teaching styles adopted at day schools were varied, but tutors described aspects of 'teaching as imparting information', 'teaching as transmitting structured knowledge', 'teaching as an interaction between the teacher and student' and 'teaching as facilitating understanding on the part of the student' [18]. Daisy justified the variety of teaching and learning activities used at day schools when stating "so you are not doing the same kinds of things each day", and this approach was common to all. The research study found the importance of day schools and the face-to-face contact as integral to success in blended learning contexts.

All tutors described taking a facilitative approach at day schools, developed around a range of studentcentred activities, showing evidence of 'teaching as facilitating understanding on the part of the student' and 'teaching as an interaction between the teacher and student'. Both individual and group activities were common to each module during day schools with tutors stressing student-centred approaches. George spoke about learners' "active participation" at day schools with Bill's comment also illustrative of a facilitative approach:

Very quickly I will get in to 'what is action research'? We have a discussion about what it is, we agree the characteristics, and will then get into some social learning, group work, where they will identify with manipulatives.

How tutors positioned themselves in relation to their learners further pointed to a facilitative approach. Four tutors described themselves as 'facilitators' with two further emphasising support for learners in applying theory and recognised good practice to work contexts. For example, Frank preferred "a facilitative, exponential approach to delivery which uses exercises and activities". A further two tutors, Ann and Daisy, described their learners as the "experts" which, again, emphasised the role of facilitator.

These student-centred activities were supplemented with some instruction, including both 'teaching as imparting information' and 'teaching as transmitting structured knowledge' [18], where understanding of key information, theory and concepts was required. For her module 'Education and the Law', Ann outlined, "I do specific delivery on equal opportunities, the new equality bill to make sure they were up to speed on that". Daisy stated, "I do tend to do a fair bit of input into areas that I think they need to know about", when discussing her teaching of equality and diversity, with this including key legislation in the area. Both examples were illustrative of transmission of information and all tutors described some instruction of key module information such as submission dates and assessment requirements.

\subsubsection{Assessment}

Day schools commonly included activities which aided assignment preparation, with this continuing outside day schools via computer mediated communications (CMCs) (see Table 2 for a summary of tutors' interaction with learners via CMCs during their modules). In all modules, learners had autonomy to direct their learning and focus on assignment work with tutors available for support. Ann 
and Claire, who received the highest CEQ scores, were (to quote Ann) "there on demand" to facilitate learners' application and analysis within work contexts. Whilst being available to learners was common to all, other tutors tried to engage learners in a variety of online activities but with limited success. Claire use discussion boards to provide feedback on assignment plans. However, minimal peer interaction was occurring via this medium. Emily described regular synchronous web conferences which had predetermined topics to discuss. Whilst these were successful in engaging learners and allowing peer interaction, the tutor explained that more practical issues were discussed around assessment and use of wider university systems. She noted the use of such software was new to her and further work was required to appropriately structure sessions. Bill encouraged the use of wikis to allow collaboration with peers to validate assignment choices, but described limited learner engagement. Two other tutors, George and Harry, encouraged the submission of assignment plans on VLE discussion boards which, was generally carried out. However, there were minimal comments from peers, and VLE analysis revealed none from the tutors. From analysis of activities outside day schools, module assessments were the key driver of student learning with these undertaken independently from peers but with support from tutors. This is considered further throughout the remainder of this section.

Table 2 - Summary of tutors' interaction with learners via CMCs during their modules.

\begin{tabular}{|l|l|}
\hline Tutor & Summary of tutors' interaction with learners via CMCs during their modules \\
\hline Ann & E-mail support. \\
\hline Bill & E-mail support, wiki to validate learner assignment plans. \\
\hline Claire & E-mail support, learner assignment plans discussed on VLE discussion boards. \\
\hline Daisy & E-mail support. \\
\hline Emily & $\begin{array}{l}\text { E-mail support, online synchronous conferences, established a group on a } \\
\text { social networking site to aid induction and learner socialisation. }\end{array}$ \\
\hline Frank & E-mail support. \\
\hline George & E-mail support, learner assignment plans added to VLE discussion boards. \\
\hline Harry & E-mail support, learner assignment plans added to VLE discussion boards. \\
\hline
\end{tabular}

High scores received on the CEQ scale Clear Goals and Standards (mean $=3.89$ ) suggested learners knew what was expected and why they were studying a particular topic, with tutors indicating the relevance of activities at day schools. Bill was illustrative of all tutors here when outlining "what's in it for me" to learners, as activities and assignments were introduced. Learners had choice over assignment focus, and all were related to practice within their organisations. Assignments were problem-based and generally case-method within learners' organisations, with examples being action research, evaluation of a piece of legislation in context, and evaluation of leadership and management structures.

All modules were structured around assessment strategies and this appeared appropriate for the needs of adult learners undertaking vocationally relevant degrees. This was evidenced from tutor comments during the interviews and analysis of VLE content, particularly module assessment guides. This simple module structure, focused around assessment, that created 'space' for learning, appeared appropriate for PT learners undertaking vocationally relevant degrees. As stated above, all learners had choice over assignment focus, and all were related to practice within their organisations. These two factors led all tutors to teach key principles but then allow learner contextualisation, principally through module assessment requirements. Ann was illustrative here when stating "the problem with a topic such as 'education and the law', is, depending on where the students were, there is no way we could put everything on a VLE or teach it at day schools", and this forced tutors into an assessment driven structure. Ann developed this point further when stating:

When the day schools were finished one of the first things I would do is go through the assessment..... and say right what I would like you to do before the 
next time I see you...... I would really like to see your case studies so I can begin formative feedback.

Ann's module assessment consisted of four small case studies about aspects of educational law and an evaluative report about the implications of legislation in learners' organisations. Following the first day school, Ann instructed learners to complete case studies before the second day school, with work commencing on reports after that. This was a common approach to structure modules around assessment requirements and appears appropriate for learners who are likely to be managing the competing pressures of work and family life. This structure enabled the spread of workload across modules, but was strengthened with tutor feedback throughout the assessment process.

Assessment strategies structured the modules with each having supporting documents and opportunities for tutors to feedback on learner progress. Modules included extensive formative assessment that involved review of an assignment plan and feedback on parts of draft assignments. Dates were established for each aspect of assessment and were generally structured around day schools, assignment plans being submitted at the second day school for example. Bill explained how he integrated assignment plans within his module, which was a common approach across all tutors:

Then the second session, there will probably be an email sent to them on what we are going to concentrate on and what I want you to be doing and I might have some project proposals to return to them. The second session would be another practically based session - how you validate your work, writing reflectively, issues of data analysis.

Clear goals and standards were apparent in detailed assessment briefs and, in a number of cases, use of exemplar material. George noted the motivational value of plans and exemplar work:

...I also think what motivates them is having things like plans for assignments, certainly motivates them and makes them feel better about doing things. They also like the idea about having a past example so that certainly helps motivate them.

This again indicated a common approach from tutors regarding an assessment driven structuring of modules and the motivational effects that was felt to have. All tutors explained that assessment strategies were motivational which was enhanced with timely and constructive feedback.

\subsubsection{Learner Support}

Structuring modules by the assessment strategies allowed greater learner autonomy than a content driven approach, however, mechanisms were in place for tutors to support learners. Blended, PT courses need to be flexible in terms of meeting learning outcomes but have sufficient structure in their delivery for learners with competing pressures from work and family life. This was evident from all the modules, particularly around assessment, but was enhanced with learner support mechanisms.

Literatures argue that in order to sustain the chosen teaching, learning and assessment, the design and management of effective student support strategies need to be embedded within the programme structure [19]. Whilst the design was around assessment strategies, active management of support, predominantly facilitated by e-mail, was evident from tutor interviews.

Five tutors, receiving the higher CEQ scores, outlined similar proactive strategies to support and encourage learners in meeting the formative and summative assessment requirements of modules. Formative assessment processes were monitored closely with e-mail, phone calls or quick chats at day schools used to prompt learners and encourage dialogue. Emily's module required completion of a number of 'mini-projects' and she outlined monitoring learners' engagement and would "chase them up", if they are not in touch, with Bill "chivvying people along if I haven't received a project proposal".

Common across all modules was learner support through feedback on formative assessments. This commonly included feedback on assignment plans and draft reports with tutor Harry illustrative:

One of the things the students have to do is to put a summary of their assignment brief onto Blackboard which is a virtual learning environment. Quite often, instead of doing it straight onto Blackboard, they will send it through on email.

Therefore, even though Harry did not contribute to the VLE discussion boards and received one of the lowest CEQ scores, he was commenting on assignment plans facilitated by e-mail. All tutors emphasised commitment to supporting learners through assessments, which was exemplified through 
response times. Emily illustrated this when stating, 'the response times were really good this year, often in the morning that it arrived. These learners appear to require a minimum level of support which involves timely and constructive feedback to formative assessments, however, tutors receiving higher CEQ scores were more proactive in communicating. This level of support was exemplified by Ann when stating:

\section{I don't know if I am soft but when I tutor with blended [learning] I do regularly send students emails and try to keep regular contact and I also make it very clear that it is their responsibility to actually contact me.}

Whilst illustrating a high level of support this comment highlights expectations of tutor and learner roles set throughout the module and the value of e-mail in blended learning.

Student support mechanisms appeared most effective when facilitated by e-mail and not by other forms of computer mediated communications (CMCs) such as wikis and discussion boards. Whilst this may be expected given e-mail's requirement of a personal response there appeared to be other factors influencing learner perceptions. The two tutors receiving the highest CEQ scores, Ann and Claire, both spoke enthusiastically about being available for learners, sending e-mails to check on progress and responding in a timely manner. This support was facilitated by e-mail, which provided immediacy and intimacy, which the two tutors found motivating for learners. Similar feedback was received from other tutors about the value of e-mail in prompting and encouraging learners, however, other communication media were less effective with both tutors and learners influencing this. One tutor established a wiki and two discussion boards for learners to showcase elements of practice and outline plans for assessment. These methods were included to elicit peer support and collaboration in the assessment process and allow peers to validate assignment plans. In each case, contributions were not part of the summative mark received for the module and limited learner engagement was evident. Further, on both discussion boards, George and Harry had not contributed or commented on individual plans or made general comments about submissions that could guide others. Although both tutors commented on learner's assignment work via e-mail, they were 'invisible' in module discussion boards and both received below average CEQ scores.

\subsection{Summary}

The research noted that an important part of the apparent general module success was the congruent nature of teaching, learning and assessment with the Individual Constructivist Perspective, which appears appropriate for learners studying PT, vocationally relevant degrees at a distance. This section has taken steps to evidence this view. The Individual Constructivist Perspective highlights the achievement of active discovery where learners construct new ideas through hypothesis testing. This was apparent from the 'facilitative' teaching style adopted by all tutors at day schools, but was further evidenced through the problem-based and case-method assessments adopted on the modules. The extent of learners working independently, particularly on module assessments, outside day schools, resonates with individual constructivism as they are student-centred, encouraging experimentation and application of theory to practice. This led to a predominant module approach of individual student-centred pedagogy aligned with problem-based learning and assessment. In addition, modules were generally structured around assessment requirements, both formative and summative. Modules included extensive formative assessment, which helped structure the modules for learners. Clear goals and standards were apparent in detailed assessment briefs, some exemplar material, with dates set for both formative and summative aspects, commonly structured around day schools. This level of structure appears appropriate for part-time, mature learners managing the influence of daily events, together with pressures and time constraints of work. High CEQ scores on scale items Clear Goals and Standards (mean = 3.89) and Good Teaching Feedback on, and Concern for, Student Learning (mean $=3.73$ ) were evidence of structured learning environments supported by timely assessment and learner feedback.

This simple module structure, focused around assessment, which created 'space' for learning, appeared appropriate for PT learners undertaking vocationally relevant degrees. Further, available tutor support, with assessment focused learner activities outside of day schools, were associated with module success. 


\section{CONCLUSION}

This paper aimed tor proposes a module approach to teaching, learning, assessment and support for learners undertaking part-time, vocational degrees. It drew on research that conducted a detailed exploration of eight tutors' practice on a blended learning module delivered to PT learners undertaking vocationally relevant qualifications. These modules were found to be successful (see Section 5.2) however, there was minimal peer engagement evident, particularly within the VLE. The paper argues that Individual Constructivist Approaches [6] were favoured by learners within the formal course confines, with a need for tutors to promote a simple module structure focused around assessment that creates 'space' for learning. In today's social media rich society, this could be a suitable approach to allow time for learners to draw further on their own Personal Learning Networks (PLN) [20]. For the purposes of this research a PLN is an informal learning network of people a learner interacts with to support some type of learning for their degree studies. This could include, but not restricted to, colleagues at work, fellow degree students, family, friends, or relative strangers connected to in online forums. The conclusion firstly outlines the suggested module approach before discussing the implications regarding learner engagement with support that is beyond the formal confines of a module.

The suggested module approach mirrors the Individual Constructivist Perspective. This Perspective highlights the achievement of active discovery where learners construct new ideas through hypothesis testing. This is supported with a 'facilitative' teaching style adopted by all tutors at day schools and with problem-based or case-method assessments. This promotes learners working independently, particularly on module assessments, outside face-to-face contexts. This further resonates with individual constructivism as this approach is student-centred, encouraging experimentation and application of theory to practice. This encourages a predominant module approach of individual student-centred pedagogy aligned with problem-based learning and assessment. This approach is enhanced with available tutor support, with assessment focused learner activities outside of day schools including formative and summative stages.

This approach contradicts the recommendations of Social Constructivist models of e-learning, which commonly promote opportunities for peer interaction within online, formal university learning environments, The Five Stage Model [4] and Networked Learning [5], for example. Learners' peer support and collaboration occurred mainly at day schools with tutors having limited success in encouraging this interaction within formal online communication media. Online strategies to encourage peer interaction included synchronous conferencing, wikis and discussion boards to showcase elements of practice and outline plans for assessment, with tutors and virtual learning environment (VLE) analysis identifying limited learner engagement.

I would argue adopting an Individual Constructivist Perspective, as suggested from the research findings, is potentially more relevant in today's social media rich societies. The research data suggested challenges for tutors to encourage learners to participate in online peer activities with the VLE analysis noting limited engagement on all modules. This does not mean, however, that learners are not communicating with peers, given the affordances of communication and social media technologies. Or that learners need to be communicating with their peers at all - support may be available through other networks, particularly as these learners are generally in work and undertaking study and assignments relevant to their professional contexts. These findings beg the following question, if learners are not engaging with peers within the formal module confines, who are the engaging with to support their degree studies?

To explore this question, exploration of learners' Personal (or Professional) Learning Network (PLN) is needed [20]. PT learners undertaking vocationally relevant qualifications could be drawing on their Professional Learning Networks quite extensively to support their studies, hence, not requiring engagement with peers within online elements of University study.

\section{REFERENCES}

[1] De George-Walker, L. \& Keeffe, M "Self-determined blended learning: a case study of blended learning design," Higher Education Research \& Development, vol. 29, no 1, pp. 1-13, 2010.

[2] Holley, D. \& Oliver, M. "Student engagement and blended learning: Portraits of risk," Computers \& Education, vol. 54, pp. 693-700, 2010. 
[3] Knowles, M. S., Holton, E. F. \& Swanson, R. A. "The Adult Learner: The Definitive Classic in Adult Education and Human Resource Development," $8^{\text {th }}$ ed., Oxford: Routledge, 2015.

[4] Salmon, G. "E-moderating: The key to teaching \& learning online," $3^{\text {rd }}$ ed., London: RoutledgeFalmer, 2011.

[5] Goodyear, P., Banks, S., Hodgson, V., \& McConnell, D. "Research on network learning: an overview," In: Goodyear, P., Banks, S., Hodgson, V., \& McConnell, D. (eds.), Advances in research on networked learning, Dordrecht: Kluwer Academic Publishers, pp. 1-10, 2004.

[6] Mayes, T. \& de Freitas, S. "Learning and e-learning: the role of theory," In: Beetham, H. \& Sharpe, R. (eds.), Rethinking Pedagogy for a Digital Age: Designing and delivering e-learning, Abingdon, Oxfordshire: Routledge, 13-25, 2007.

[7] Creswell, J. W.; Plano Clark, V. L. "Designing and conducting mixed methods research." Sage Publications, London, 2007.

[8] Ramsden, P. "A performance indicator of teaching quality in higher education: The Course Experience Questionnaire," Studies in Higher Education, vol. 16, pp. 129-150, 1991.

[9] Biggs, J. "Teaching for Quality Learning at University," $2^{\text {nd }}$ ed., Maidenhead: Open University Press, 2003.

[10] Siemens, G. (2005) Connectivism: a learning theory for the digital age [Online] Available at: http://www.elearningspace.org/Articles/connectivism.htm [Accessed: 11 December 2015].

[11] Beetham, H. \& Oliver, M. "The Changing Practices of Knowledge and Learning", In: Sharpe, R., Beetham, H. \& De Freitas, S. (eds.), Rethinking Learning for a Digital Age, Oxford: Routledge, pp. 155-169, 2010.

[12] Devlin, M. \& Samarawickrema, G. "The criteria of effective teaching in a higher education context," Higher Education Research \& Development, vol. 29, no. 2, pp. 111-124, 2010.

[13]Biggs, J. B., Kember, D. \& Leung, D. Y. P. "The revised two-factor Study Process Questionnaire: R-SPQ-2F," British Journal of Educational Psychology, vol. 71, pp. 133-149, 2001.

[14]Beetham, H. \& Sharpe, R. (eds.), Rethinking Pedagogy for a Digital Age: Designing and delivering e-learning, Abingdon, Oxfordshire: Routledge, pp. 13-25.

[15] Fox, R. "Constructivism Examined," Oxford Review of Education, vol. 27, no 1, pp. 23-35, 2001.

[16] Beetham, H. "Institutional Approaches to Curriculum Design: Full Synthesis Report" [online] Available at: http://repository.jisc.ac.uk/5081/1/JISC_Curriculum_Design_Final_Synthesis_i1.pdf [Accessed: 13 February 2015], 2012

[17] Mayes, T. \& de Freitas, S. "JISC e-learning Models Desk Study: Stage 2: Review of e-learning theories, frameworks and models" [online] Available at: http://www.jisc.ac.uk/uploaded_documents/Stage\%202\%20Learning\%20Models\%20(Version\%20 1).pdf [Accessed 21 January 2015], 2004.

[18] Kember, D. "A reconceptualisation of the research into university academics' conceptions of teaching, Learning and Instruction, vol, 7, no 3, pp. 255-275, 1997.

[19] Stubbs, M., Martin, I. \& Endlar, L., "The structuration of blended learning: putting holistic design principles into practice," British Journal of Educational Technology, vol. 37, no. 2, pp. 163-175, 2006.

[20] Wheeler, S, “Learning with 'e's," Crown House Publishing, Carmarthen, 2015. 